Mehran Roxana (Orcid ID: 0000-0002-2012-4137)

Yudi Matias (Orcid ID: 0000-0002-3706-4150)

Sharma Samin (Orcid ID: 0000-0002-1888-0793)

Kini Annapoorna (Orcid ID: 0000-0002-7189-3307)

Dangas George (Orcid ID: 0000-0001-7502-8049)

\title{
The Importance of the Heart Team Evaluation Before Transcatheter Aortic Valve Replacement: Results from the BRAVO-3 Trial
}

Anton Camaj MD, $\mathrm{MS}^{1}$, Bimmer E Claessen, MD, $\mathrm{PhD}^{1}$, Roxana Mehran, $\mathrm{MD}^{1}$, Matias B Yudi, MBBS$^{2}$, David Power, MBBS ${ }^{1}$, Usman Baber, MD, MS ${ }^{1}$, Christian Hengstenberg, $\mathrm{MD}^{3}$, Thierry Lefevre, $\mathrm{MD}^{4}$, Eric Van Belle, $\mathrm{MD}, \mathrm{PhD}^{5}$, Gennaro Giustino, $\mathrm{MD}^{1}$, Paul Guedeney, $\mathrm{MD}^{6}$, Sabato Sorrentino, $\mathrm{MD}, \mathrm{PhD}^{7}$, Christian Kupatt, $\mathrm{MD}^{8}$, John G Webb, $\mathrm{MD}^{9}$, David HildickSmith, $\mathrm{MD}^{10}$, Hans Ulrich Hink, MD ${ }^{11}$, Efthymios N Deliargyris, MD ${ }^{12}$, Prodromos Anthopoulos, $\mathrm{MD}^{13}$, Samin K Sharma, $\mathrm{MD}^{1}$, Annapoorna Kini, $\mathrm{MD}^{1}$, Samantha Sartori, $\mathrm{PhD}^{1}$, Jaya Chandrasekhar, $\mathrm{MBBS}^{1}$, George Dangas, MD, $\mathrm{PhD}^{1}$

1. The Zena and Michael A. Wiener Cardiovascular Institute, Icahn School of Medicine at Mount Sinai, New York, New York; 2. Austin Health, Heidelberg, Victoria, Australia; 3. DZHK (German Centre for Cardiovascular Research), partner site Munich Heart Alliance, Munich, Germany, and Deutsches Herzzentrum München, Technische Universität München, Munich, Germany; 4. Institut Cardio Vasculaire Paris Sud, Hôpital Privé Jacques Cartier, Massy, France; 5. Department of Cardiology and INSERM UMR 1011, University Hospital, and CHRU Lille, Lille, France; 6. Sorbonne Université, ACTION Study Group, INSERM UMRS_1166 Institut de cardiologie (AP-HP), Paris, France; 7. Division of Cardiology, Department of Medical and Surgical Sciences, Magna Graecia University, Catanzaro, Italy; 8. LMU Munich, Munich,

This is the author manuscript accepted for publication and has undergone full peer review but has not been through the copyediting, typesetting, pagination and proofreading process, which may lead to differences between this version and the Version of Record. Please cite this article as doi: $10.1002 / \operatorname{ccd} .28717$

This article is protected by copyright. All rights reserved. 
Germany; 9. St. Paul’s Hospital, Vancouver, British Columbia, Canada; 10. Sussex Cardiac Centre-Brighton \& Sussex University Hospitals NHS Trust, Brighton, East Sussex, United Kingdom; 11. Universitätsmedizin Mainz, Mainz, Germany; and 12. Science and Strategy Consulting Group, Basking Ridge, New Jersey; 13. Arena Pharmaceuticals, Inc., Zurich, Switzerland.

Short Title: Heart Team Evaluation Before TAVR

Financial disclosures: Dr. Dangas has received grants (to the institution) from The Medicines Company (modest level) and his spouse is a consultant and advisory board member for Abbott Vascular. Dr. Mehran has received grants (to the institution) from The Medicines Company (modest level) and is a consultant and advisory board member for Abbott Vascular. Dr. Anthopoulos and Dr. Deliargyris were employees of The Medicines Company at the time of the original BRAVO-3 trial. None of the other authors have any disclosures relevant to this particular project.

Keywords: TAVR, Heart Team, Logistic EuroSCORE

Word Count: Abstract-250, Manuscript—3,456

\section{Corresponding author:}

This article is protected by copyright. All rights reserved. 


\section{George D. Dangas, MD, PhD}

The Icahn School of Medicine at Mount Sinai,

One Gustave L. Levy place, Box 1030, New York, NY 10029

Phone: 212-659-9641, Fax: 646-537-8547, Email: george.dangas@mountsinai.org 


\begin{abstract}
Background/Objectives: Clinicians use validated scores to risk-stratify patients undergoing TAVR. However, evaluation by the Heart Team often deems patients to be at higher risk than their formal scores suggest. We sought to assess clinical outcomes of TAVR patients defined as high-risk by the Heart Team’s assessment versus the patient’s logistic EuroSCORE (LES).

Methods: The BRAVO-3 trial randomized patients at high risk (LES $\geq 18$, or deemed inoperable by the Heart Team) to TAVR with periprocedural anticoagulation with unfractionated heparin versus bivalirudin. Endpoints included net adverse cardiac events (NACE: the composite of allcause mortality, MI, stroke or bleeding), major adverse cardiovascular events (MACE: death, MI or stroke), the individual components of MACE, major vascular complications, BARC $\geq 3 \mathrm{~b}$ bleeding and VARC life-threatening bleeding at 30 days. We compared patients deemed highrisk based on LES $\geq 18$ vs. high-risk by the Heart Team despite lower LES.
\end{abstract}

Results: A total of 467/800 (58.4\%) patients were deemed high-risk by the Heart Team despite LES $<18$. After multivariable analysis, there were no differences in the odds of endpoints between groups (NACE, OR $\mathrm{LES}_{218}: 1.32$, 95\% CI 0.86-2.02, p=0.21; MACE, $\mathrm{OR}_{\mathrm{LES} \geq 18:}$ 1.27,

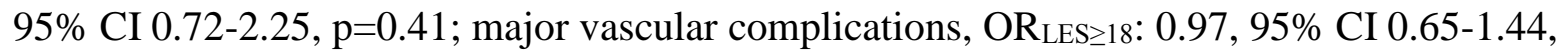
$\mathrm{p}=0.88 ; \mathrm{BARC} \geq 3 \mathrm{~b}, \mathrm{OR}_{\mathrm{LES}} \geq 18: 1.38,95 \% \mathrm{CI}$ 0.82-2.33, $\mathrm{p}=0.23$; and VARC life-threatening bleeding, OR $\mathrm{LES} \geq 18$ : 0.99, 95\% CI 0.69-1.41, $\mathrm{p}=0.95)$.

This article is protected by copyright. All rights reserved. 
Conclusion: Patients undergoing TAVR and labeled high-risk by LES $\geq 18$ or Heart Team assessment despite LES $<18$ have comparable short-term outcomes. Assignment of high-risk status to over $50 \%$ of patients is attributable to Heart Team's clinical assessment. 


\section{Abbreviations}

TAVR: Transcatheter Aortic Valve Replacement

SAVR: Surgical Aortic Valve Replacement

LVEF: Left Ventricular Ejection Fraction

PCI: Percutaneous Coronary Intervention

GFR: Glomerular Filtration Rate

CKD: Chronic Kidney Disease

COPD: Chronic Obstructive Pulmonary Disease

PVD: Peripheral Vascular Disease

CAD: Coronary Artery Disease

CABG: Coronary Artery Bypass Graft

This article is protected by copyright. All rights reserved. 


\section{Introduction}

The ability to carefully risk-stratify patients prior to transcatheter aortic valve replacement (TAVR) is invaluable during the selection of patients who will undergo the procedure. Given the procedure's rapidly rising popularity, the appropriate risk stratification of TAVR patients is becoming evermore important. ${ }^{1-7}$ When confronted with this task, multidisciplinary Heart Teams will routinely calculate one or many validated risk scores to objectively risk-stratify patients. ${ }^{8}$ The European System for Cardiac Operative Risk Evaluation (logistic EuroSCORE) is one of the more commonly employed risk scores used to risk-stratify patients prior to TAVR despite being developed based on data from cardiac surgery patients predominantly undergoing coronary artery bypass graft surgery. ${ }^{9,10}$ While the logistic EuroSCORE (LES) has been shown to overestimate operative mortality risk in patients undergoing TAVR, ${ }^{11}$ there are also scenarios where a low LES misaligns with the Heart Team's overall clinical evaluation of a patient who is otherwise deemed higher risk than his/her LES would suggest due to clinical risk factors that formal risk scores fail to capture. ${ }^{3}$ This low precision can largely be explained by the LES’s lack of TAVR-specific variables.

In light of these discrepancies, it is important to unravel the clinical utility in risk-stratifying a patient as high-risk despite having a low risk LES score. Indeed, the BRAVO (Effect of Bivalirudin on Aortic Valve Intervention Outcomes)-3 randomized trial demonstrated that a majority of patients who underwent transfemoral-TAVR (TF-TAVR) were deemed high surgical risk or inoperable by the Heart Team as opposed to a LES $\geq 18 .{ }^{12}$ Consequently, the goal of the

This article is protected by copyright. All rights reserved. 
present BRAVO-3 subgroup analysis was to compare the short-term clinical outcomes of highrisk patients as defined by their high LES scores or Heart Team assessment despite lower LES scores undergoing TF-TAVR.

\section{Materials and Methods}

BRAVO-3 was an open-label, randomized, controlled trial comparing bivalirudin with unfractionated heparin (UFH) in 802 high-risk or inoperable patients undergoing TAVR in 31 European and North American sites. The results have been reported previously. ${ }^{12,13}$ The local ethics committee at each site approved the study.

\section{Study Population}

Patients with severe aortic stenosis (AS) who were $\geq 18$ years of age, at high surgical risk defined as a European System for Cardiac Operative Risk Evaluation score (logistic EuroSCORE) of $\geq 18$, or deemed inoperable by the Heart Team, and scheduled for TAVR via transfemoral approach were eligible for enrollment. The key exclusion criteria were planned surgical cut down for access; common femoral artery minimal luminal diameter $<6.5 \mathrm{~mm}$; presence of a previous mechanical or mitral bioprosthetic valve; left ventricular ejection fraction (LVEF) <15\%; severe aortic or mitral regurgitation; concomitant PCI; recent bleeding or neurological event; and dialysis dependence.

\section{Study Medications}

This article is protected by copyright. All rights reserved. 
In patients with estimated glomerular filtration rate (GFR) $\geq 60 \mathrm{ml} / \mathrm{min}$, bivalirudin was given as an initial bolus of $0.75 \mathrm{mg} / \mathrm{kg}$, followed by a continuous infusion of $1.75 \mathrm{mg} / \mathrm{kg} / \mathrm{hr}$ that was stopped after successful TAVR. Patients with GFR $<60 \mathrm{ml} / \mathrm{min}$ received a lower adjusted infusion rate. UFH administration was recommended to be titrated to a target activated clotting time of > 250 sec; at the operator's discretion protamine was given at the end of the procedure for reversal of UFH action. Patients underwent TAVR according to the standard procedure at each site, including selection of a commercially available TAVR valve and periprocedural use of antithrombotic medications. The protocol recommended use of low dose aspirin 75-100 mg/day for at least 1 year and clopidogrel $75 \mathrm{mg} /$ day for a period defined by local practice post-TAVR.

\section{Study Endpoints}

For the present analysis, we investigated all outcomes available in the original BRAVO-3 Trial at 48 hours or before discharge and at 30 days. These included net adverse cardiac events (NACE; defined as the composite of all-cause mortality, MI, stroke or bleeding), major adverse cardiovascular events (MACE; defined as death, MI or stroke), the individual components of MACE, major vascular complications, BARC $\geq 3 \mathrm{~b}$ bleeding and VARC life-threatening bleeding.

\section{Statistical Analysis}

We compared patients deemed high-risk due to LES $\geq 18$ and patients deemed high-risk by the Heart Team despite otherwise lower LES. Baseline clinical, demographic and procedural characteristics of the study groups were reported as mean $\pm \mathrm{SD}$ for continuous variables and as 
proportions for categorical variables. Continuous variables were compared using the Student's $t$ test. Categorical variables were compared with the $\chi 2$ test. The logistic EuroSCORE (European System for Cardiac Operative Risk Evaluation) was calculated using a logistic-regression equation, with higher scores indicating greater surgical risk. ${ }^{12}$ We performed multivariable logistic regression analysis to identify independent predictors of 48-hour and 30-day events with resultant adjusted odds ratios and 95\% confidence intervals for each variable. In our multivariable models, we included the following predictors: LES $\geq 18$, sex, age (per year), diabetes mellitus, chronic kidney disease (CKD), COPD, left ventricular ejection fraction, atrial fibrillation and country. Statistical analyses were performed using STATA version 14.0 (College station, TX). P-values $<0.05$ were considered significant.

\section{Results}

Baseline Clinical \& Procedural Characteristics

Overall, 800 of the 802 patients that were randomized in the BRAVO-3 study were included in the present study. Of these 800 patients, a majority (58.4\%) was deemed high-risk or inoperable and therefore eligible for TAVR according to Heart Team assessment despite LES $<18$ and 333 (41.6\%) were deemed high-risk or inoperable and therefore eligible for TAVR according to LES $\geq 18$ (Table 1). Figures 1A and 1B show the distribution of the LES between the group which was deemed high risk by a LES $\geq 18$ and the group which was deemed high risk by Heart Team assessment (LES <18). Baseline clinical and procedural characteristics are reported in Table 1. There were several differences between groups. Patients subjectively deemed as high-risk by the 
Heart Team were younger than their objectively high-risk counterparts. Those eligible for TAVR according to Heart Team assessment despite LES $<18$ had a higher baseline LVEF. Additionally, patients eligible for TAVR according to Heart Team assessment despite LES $<18$ were less likely to require periprocedural general anesthesia, but were more likely to undergo balloon postdilation following TAVR.

\section{Outcomes}

The crude event rates for all outcomes are reported in Table 2. There were no significant differences in the adjusted event rates between the Heart Team group vs. the LES group (Table 3) at 48 hours or before discharge, or at 30 days.

\section{Discussion}

The main findings of this subgroup analysis of the BRAVO-3 open-label, randomized controlled trial are (1) a majority of patients undergoing TAVR were deemed high-risk by Heart Team assessment rather than LES; and (2) patients deemed high-risk by the Heart Team despite otherwise lower LES appear to have similar short-term outcomes compared to those patients deemed high-risk by LES $\geq 18$. Our findings suggest that clinical assessment by a multidisciplinary Heart Team remains a highly valued tool in the preoperative evaluation and risk stratification of TAVR patients given its ability to account for clinical risk factors left out of formal risk score calculators.

Efficacy of Logistic EuroSCORE 
The Logistic EuroSCORE has been used in landmark trials of TAVR as a means of predicting 30-day morbidity and mortality. Although the LES is primarily a surgical risk score intended to evaluate risk of surgical outcomes, landmark TAVR trials have demonstrated its correlation with 30-day mortality also in patients undergoing TAVR across gradations of preoperative risk (Supplemental Table). While our results point to similar short-term outcomes between those deemed high-risk based on a LES $\geq 18$ versus those deemed high-risk based upon Heart Team appraisal, previous work has demonstrated that the LES considerably over-estimates operative mortality in TAVR as well as SAVR populations when compared to other validated surgical risk scores. ${ }^{14}$ In a recent meta-analysis of contemporary risk scores for TAVR by Wang et al. the investigators found a pooled odds ratio of 0.31 (95\% CI 0.25-0.38) between the observed and predicted risk for the LES. This was substantially different from that of other surgical risk scores including the EuroSCORE II (OR 1.26, 95\% CI 1.06-1.51) and STS Score (OR 0.95, 95\% CI 0.72-1.27). ${ }^{8}$ Although these initial findings would suggest that the EuroSCORE II and STS Score may be superior to the LES, Wang et al. further showed that the these surgical risk scores only weakly discriminated operative mortality after TAVR with a pooled c-statistic of 0.62 , limiting our ability to apply these scores to TAVR patients. Efforts to address this issue by designing TAVR-specific risk models, ${ }^{15-19}$ while promising, have not been shown to be superior to their surgical counterparts in external validation studies. ${ }^{20,21}$

\section{The Heart Team}


Since the FDA approved TAVR for the management of severe AS in patients deemed inoperable, TAVR programs have experienced significant improvements in volume and outcomes, which can be attributed to both continuous refinements to the patient selection process and clinical trials demonstrating the procedure's efficacy in lower-risk patients. The multidisciplinary Heart Team approach in TAVR has also been hailed as a cornerstone of the procedure's growing success. ${ }^{23}$ As it stands, the goal of the Heart Team is to provide a multidisciplinary, patient-centered approach to the initial evaluation of the individual with severe AS in order to select the optimal management strategy as well as assess the risk of adverse outcomes following the chosen intervention. ${ }^{24}$ The 2017 AHA/ACC Focused Update of the 2014 AHA/ACC Guideline for the Management of Patients With Valvular Heart Disease provides a Class I, Level C recommendation for the presence of a heart valve team during the choice of intervention. ${ }^{7}$ In this regard, there is a low level of evidence guiding how to appropriately select high risk patients for TAVR vs. SAVR. Here, we present data demonstrating that the "Heart Team” approach is appropriate in selecting the optimal treatment strategy for these complex patients.

In the present study, a majority (58.4\%) of the patients were deemed high-risk by the Heart Team despite being younger and less likely to have COPD, peripheral vascular disease, coronary artery disease, prior CABG, atrial fibrillation and poor renal function than their objectively high-risk counterparts. These results are in line with international and specialty guidelines and indicate that the overall clinical assessment of a patient's risk should involve a multidisciplinary Heart Team 
approach that accounts for other patient characteristics that contemporary surgical risk scores fail to capture. ${ }^{7,22}$ One characteristic that has been left out of surgical risk scores, but can generally be gauged clinically by a Heart Team, is a patient's functional assessment or measure of frailty. Multiple studies have shown frailty measures to be associated with improved risk stratification in patients undergoing TAVR. ${ }^{26-35}$ In this context, Schoenenberger, et al. evaluated whether a frailty index (based on assessment of cognition, mobility, nutrition, and activities of daily living with either) in combination with conventional surgical risk scores improves 1-year mortality prediction in patients undergoing TAVR. ${ }^{36}$ The investigators found that a combination of the frailty index with either the LES or STS score improved mortality prediction at 1 year underscoring the importance of a comprehensive evaluation, including both an assessment by the Heart Team and risk score calculation, of patients being considered for TAVR. The observed additive value may largely be a result of the fact that these risk scores tend to be predictors of mortality while Heart Teams base their assessments on risk of morbidity and mortality. Our findings suggest that the clinical gestalt of an experienced multidisciplinary Heart Team appears to capture an important cohort of high-risk TAVR candidates otherwise missed by leading risk stratification systems.

Recently, two trials in low-risk patients showed TAVR to be at least non-inferior to SAVR even in a low-risk cohort. ${ }^{37,38}$ In addition, another recent study demonstrated an inverse relationship between center volume and 30-day mortality following TAVR with centers in the lowest quartile of TAVR procedures having worse outcomes, ${ }^{39}$ highlighting the notion that the Heart Team's 
assessment of patients can differ greatly between a highly experienced TAVR center and a less experienced TAVR center. Beyond clinical trial data, details of anatomy, clinical characteristics, and patient values may further influence the favored choice in each case, and a Heart Team evaluation of each patient with severe aortic stenosis is likely to benefit the individual patient. Taken together, these clinical nuances support efforts for new, validated and reliable TAVRspecific risk scores in patients to enhance the Heart Team's evaluation.

\section{Limitations}

Our findings should be considered in light of the following limitations. First, this was a retrospective, subgroup analysis of the BRAVO-3 trial and is therefore underpowered to evaluate outcomes as stratified by LES. Second, the present study only analyzed one validated risk score

and, consequently, these results are not generalizable to studies using other risk scores. Third, we do not know if the similar outcomes noted in our study are related to the TAVR approach or to the fact that the Heart Team is able to capture additional comorbidities associated with a poor outcome not otherwise captured by the LES. Fourth, BRAVO-3 only included patients deemed high-risk for surgery and these results may not be applicable to low-to-intermediate risk patients. Finally, we only report results up to 30 days, but we acknowledge that the LES has been shown to be a better predictor of late outcomes following TAVR. ${ }^{36}$

\section{Conclusion}


In this subgroup analysis of the BRAVO-3 trial, we found no differences in short-term clinical outcomes of patients identified as high-risk due to LES $\geq 18$ compared to patients deemed highrisk by Heart Team assessment despite their lower LES $(<18)$. These findings suggest that the Heart Team approach improves risk stratification of patients deemed lower risk according to LES by incorporating frailty and other high-risk patient characteristics in the clinical decisionmaking surrounding TAVR. Therefore, the Heart Team approach should remain an integral component in the management of patients with symptomatic, severe aortic stenosis, and not be disregarded in favor of sophisticated risk scores. 


\section{References}

1. Leon MB, Smith CR, Mack M, Miller DC, et al. Transcatheter aortic-valve implantation for aortic stenosis in patients who cannot undergo surgery. N Engl J Med 2010;363:1597-607.

2. Smith CR, Leon MB, Mack MJ, Miller DC, et al. Transcatheter versus surgical aortic-valve replacement in high-risk patients. N Engl J Med 2011;364:2187-98.

3. Adams DH, Popma JJ, Reardon MJ, Yakubov SJ, et al. Transcatheter aortic-valve replacement with a self-expanding prosthesis. N Engl J Med 2014;371:967-8.

4. Arora S, Misenheimer JA, Jones W, Bahekar A, et al. Transcatheter versus surgical aortic valve replacement in intermediate risk patients: a meta-analysis. Cardiovasc Diagn Ther 2016;6:241-9.

5. Leon MB, Smith CR, Mack MJ, Makkar RR, et al. Transcatheter or Surgical Aortic-Valve Replacement in Intermediate-Risk Patients. N Engl J Med 2016;374:1609-20.

6. Reardon MJ, Van Mieghem NM, Popma JJ, Kleiman NS, et al. Surgical or Transcatheter Aortic-Valve Replacement in Intermediate-Risk Patients. N Engl J Med 2017;376:1321-31.

7. Nishimura RA, Otto CM, Bonow RO, Carabello BA, et al. 2017 AHA/ACC Focused Update of the 2014 AHA/ACC Guideline for the Management of Patients With Valvular Heart Disease: A Report of the American College of Cardiology/American Heart Association Task Force on Clinical Practice Guidelines. J Am Coll Cardiol 2017;70:252-89.

This article is protected by copyright. All rights reserved. 
8. Wang TK, Wang MT, Gamble GD, Webster M, Ruygrok PN. Performance of contemporary surgical risk scores for transcatheter aortic valve implantation: a meta-analysis. Int J Cardiol 2017;236:350-5.

9. Nashef SA, Roques F, Michel P, Gauducheau E, Lemeshow S, Salamon R. European system for cardiac operative risk evaluation (EuroSCORE). Eur J Cardiothorac Surg 1999;16:9-13.

10. Roques F, Michel P, Goldstone AR, Nashef SAM. The logistic EuroSCORE. Eur Heart J. 2003 May;24(9):881-2.

11. Osswald BR, Gegouskov V, Badowski-Zyla D, Tochtermann U, et al. Overestimation of aortic valve replacement risk by EuroSCORE: implications for percutaneous valve replacement. Eur Heart J 2009;30:74-80.

12. Dangas GD, Lefevre T, Kupatt C, Tchetche D, et al., for the BRAVO-3 Investigators. Bivalirudin versus heparin anticoagulation in transcatheter aortic valve replacement: the randomized BRAVO-3 trial. J Am Coll Cardiol 2015;66:2860-8.

13. Sergie Z, Lefevre T, Van Belle E, Kakoulides S, et al. Current periprocedural anticoagulation in transcatheter aortic valve replacement: could bivalirudin be an option? Rationale and design of the BRAVO 2/3 studies. J Thromb Thrombolysis 2013;35:483-93.

14. Parolari A, Pesce LL, Trezzi M, Cavallotti L, et al. EuroSCORE performance in valve surgery: a meta-analysis. Ann Thorac Surg 2010;787-793.

This article is protected by copyright. All rights reserved. 
15. van Mieghem NM, Head SJ, van der Boon RM, Plazza N, et al. The SURTAVI model: proposal for a pragmatic risk stratification for patients with severe aortic stenosis. EuroIntervention 2012;258-266.

16. Capodanno D, Barbanti M, Tamburino C, D’Errigo P, et al. A simple risk tool (the OBSERVANT score) for prediction of 30-day mortality after transcatheter aortic valve replacement. Am J Cardiol 2014;1851-1858.

17. D'Ascenzo F, Capodanno D, Tarantini G, Nijhoff F, et al. Usefulness and validation of the survival posT TAVI score for survival after transcatheter aortic valve implantation for aortic stenosis. Am J Cardiol 2014;1867-1874.

18. Debonnaire P, Fusini L, Wolterbeek R, Kamperidis V, et al. Value of the "TAVI2-SCORe" versus surgical risk scores for prediction of one year mortality in 511 patients who underwent transcatheter aortic valve implantation. Am J Cardiol 2015;234-242.

19. Hermiller JB, Yakubov SJ, Reardon MJ, Deeb GM, et al. Predicting early and late mortality after transcatheter aortic valve replacement. J Am Coll Cardiol 2016;343-352.

20. Hashmi IH, Hammad S, Rajagopal R, Croft D, et al. Is SURTAVI risk model a step towards ‘TAVI risk score’: time to rethink? Heart 2013;A86-A87.

21. Zbroński K, Huczek A, Puchta D, Paczwa K, et al. Outcome prediction following transcatheter aortic valve implantation: multiple risk scores comparison. Cardiol J 2016;169_ 177. 
22. Baumgartner H, Falk V, Bax JJ, De Bonis M, et al. 2017 ESC/EACTS Guidelines for the management of valvular heart disease, Eur Heart J 2017;38:2739-2791.

23. Bergmann T, Sengupta PP, Narula J. Is TAVR ready for the global aging population? Glob Heart. 2017 Dec;12(4):291-299. doi: 10.1016/j.gheart.2017.02.002.

24. Holmes DR Jr, Rich JB, Zoghbi WA, Mack MJ. The heart team of cardiovascular care. J Am Coll Cardiol. 2013 Mar 5;61(9):903-7. doi: 10.1016/j.jacc.2012.08.1034.

25. Kaier, K, Gutmann, A, Vach, W, et al. “Heart Team” decision making in elderly patients with symptomatic aortic valve stenosis who underwent AVR or TAVI—a look behind the curtain. Results of the prospective TAVI Calculation of Costs Trial (TCCT). Eurointervention. 2015;11(7):793-798.

26. Rodés-Cabau J, Webb JG, Cheung A, Ye J, et al. Transcatheter aortic valve implantation for the treatment of severe symptomatic aortic stenosis in patients at very high or prohibitive surgical risk: acute and late outcomes of the multicenter Canadian experience. J Am Coll Cardiol 2010;55:1080-90.

27. Stortecky S, Schoenenberger AW, Moser A, Kalesan B, et al. Evaluation of multidimensional geriatric assessment as a predictor of mortality and cardiovascular events after transcatheter aortic valve implantation. J Am Coll Cardiol Intv 2012;5:489-96.

28. Green P, Woglom AE, Genereux P, Daneault B, et al. The impact of frailty status on survival after transcatheter aortic valve replacement in older adults with severe aortic stenosis: a single-center experience. JACC Cardiovasc Interv. 2012;5:974-981.

This article is protected by copyright. All rights reserved. 
29. Green P, Woglom AE, Genereux P, Maurer MS, et al. Gait speed and dependence in activities of daily living in older adults with severe aortic stenosis. Clin Cardiol. 2012;35:307-314.

30. Green P, Cohen DJ, Généreux P, McAndrew T, et al. Relation between six-minute walk test performance and outcomes after transcatheter aortic valve implantation (from the PARTNER Trial). Am J Cardiol. 2013, http://dx.doi.org/10.1016/j.amjcard.2013.04.046.

31. Schoenenberger AW, Stortecky S, Neumann S, Moser A, et al. Predictors of functional decline in elderly patients undergoing transcatheter aortic valve implantation (TAVI). Eur Heart J 2013;34:684-92.

32. Arnold SV, Reynolds MR, Lei Y, et al., PARTNER Investigators. Predictors of poor outcomes after transcatheter aortic valve replacement: results from the PARTNER (Placement of Aortic Transcatheter Valve) trial. Circulation 2014;129:2682-90.

33. Kleczynski P, Dziewierz A, Bagienski M, et al. Impact of frailty on mortality after transcatheter aortic valve implantation. Am Heart J 2017;185:52-8.

34. Shimura T, Yamamoto M, Kano S, et al. Impact of the Clinical Frailty Scale on outcomes after transcatheter aortic valve replacement. Circulation 2017;135:2013-24.

35. Schoenenberger AW, Moser A, Bertschi D, et al. Improvement of Risk Prediction After Transcatheter Aortic Valve Replacement by Combining Frailty With Conventional Risk Scores. J Am Coll Cardiol Intv 2018;11:395-403. 
36. Gilard M, Eltchaninoff H, Donzeau-Gouge P, et al. Late Outcomes of Transcatheter Aortic Valve Replacement in High-Risk Patients: The FRANCE-2 Registry. J am Coll Cardiol 2016;68:1637-47.

37. Popma JJ, Deeb GM, Yakubov SJ, et al. Transcatheter Aortic-Valve Replacement with a Self-Expanding Valve in Low-Risk Patients. N Engl J Med 2019; 380:1706-1715.

38. Mack MJ, Leon MB, Thourani VH, et al. Transcatheter Aortic-Valve Replacement with a Balloon-Expandable Valve in Low-Risk Patients. N Engl J Med 2019; 380:1695-1705.

39. Vemulapalli S, Carroll JD, Mack MJ, et al. Procedural Volume and Outcomes for Transcatheter Aortic-Valve Replacement. N Engl J Med 2019; 380:2541-50. 


\section{Figure Legends}

Figure 1. Distribution of Logistic EuroSCORE in Patients with Logistic EuroSCORE <18 (A) and Logistic EuroSCORE >=18 (B). 1A: Mean: 10.2, standard deviation: 4.1, median: 10.1. 1B: Mean: 26.7, standard deviation: 8.6, median: 24.3.
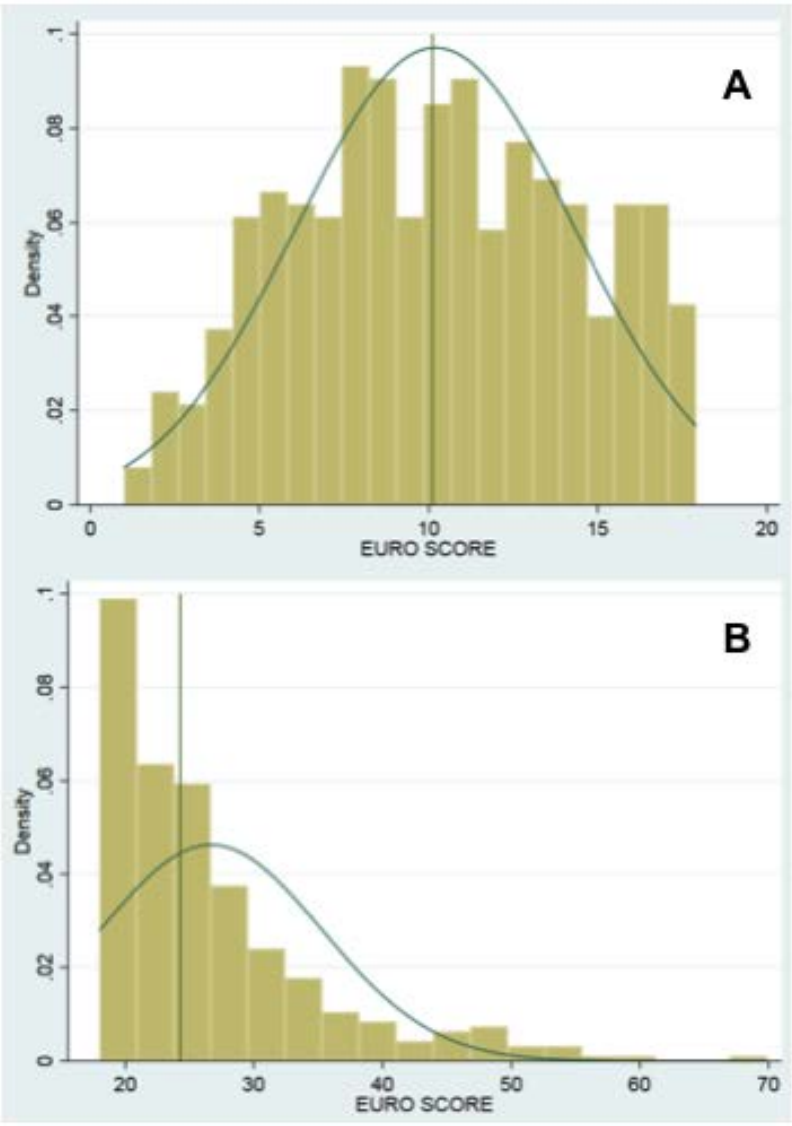
Table 1: Patient baseline clinical and procedural characteristics

\section{TAVR Eligibility According}

to

\section{Heart Team Assessment \\ Despite LES $<18$}

Logistic EuroSCORE

Age (years)

Female Gender

LV Ejection Fraction (\%)

COPD

Diabetes Mellitus

Peripheral Vascular Disease

Coronary Artery Disease

Prior Myocardial Infarction

Prior Bypass Surgery

Prior Stroke/TIA

Atrial Fibrillation

GFR $<30 \mathrm{ml} / \mathrm{min}$

GFR $30-59 \mathrm{ml} / \mathrm{min}$

General Anesthesia

Balloon Expandable Valve

Self-Expandable Valve

Balloon post-dilation

Successful Vascular Closure

$10.2 \pm 4.1$

$81.3 \pm 6.8$

$226(48.4)$

$56.0 \pm 11.6$

75 (16.1)

133 (28.5)

46 (9.9)

$221(47.4)$

$61(13.2)$

$43(9.2)$

$43(9.2)$

170 (36.4)

19 (4.1)

209 (44.8)

$157(34.0)$

$303(66.0)$

$156(34.0)$

132 (28.3)

422 (91.5)
TAVR Eligibility According

to $\operatorname{LES} \geq 18$

P-Value

( $\mathbf{N}=333)$

$26.7 \pm 8.6$

$83.7 \pm 5.8$

$-$

163 (49.0)

$<0.001$

$50.3 \pm 13.7$

0.88

$80(24.0)$

0.005

106 (31.8)

0.31

73 (21.9)

$<0.001$

183 (55.0)

0.04

55 (16.7)

0.18

74 (22.2)

$<0.001$

40 (12.0)

0.43

162 (48.7)

0.002

21 (6.3)

$<0.001$

188 (56.5)

$<0.001$

151 (46.2)

0.002

196 (60.9)

0.14

126 (39.1)

0.14

66 (19.8\%)

0.006

303 (92.7)

0.08

LES: Logistic EuroSCORE, LV: Left Ventricular, COPD: Chronic Obstructive Pulmonary Disease, TIA:

Transient Ischemic Attack, GFR: Glomerular Filtration Rate, TAVR: Transcatheter Aortic Valve Replacement

This article is protected by copyright. All rights reserved. 
Table 2. Rate of Efficacy Endpoints

\section{TAVR Eligibility According to Heart Team Assessment Despite LES < 18 $\mathbf{N}=467$}

\section{8 hours or at discharge}

NACE

MACE

Death

MI

Stroke

Major vascular complications

BARC $\geq 3 b$

VARC life-threatening bleeding
$42(8.99 \%)$

$14(3.00 \%)$

$7(1.50 \%)$

$1(0.21 \%)$

$7(1.50 \%)$

$36(7.71 \%)$

$32(6.85 \%)$

$91(19.49 \%)$
TAVR Eligibility

According to $\mathrm{LES} \geq \mathbf{1 8} \quad$ P-value

$\mathbf{N}=\mathbf{3 3 3}$

\section{0 days}

NACE

MACE

Death

MI

Stroke

Major vascular complications

$\mathrm{BARC} \geq 3 \mathrm{~b}$

VARC life-threatening bleeding

$$
\begin{gathered}
63(13.49 \%) \\
31(6.64 \%) \\
22(4.71 \%) \\
4(0.86 \%) \\
11(2.36 \%) \\
39(8.35 \%) \\
41(8.78 \%)
\end{gathered}
$$$$
119 \text { (25.48\%) }
$$

$\begin{array}{cc}43(12.91 \%) & 0.08 \\ 19(5.71 \%) & 0.06 \\ 7(2.10 \%) & 0.52 \\ 4(1.20 \%) & 0.08 \\ 8(2.40 \%) & 0.35 \\ 35(10.51 \%) & 0.19 \\ 31(9.31 \%) & 0.20 \\ 71(21.32 \%) & 0.52\end{array}$

0.08

0.52

0.08

0.35

0.19

0.52

LES: Logistic EuroSCORE, NACE: Net Adverse Cardiovascular Events, MACE: Major Adverse Cardiovascular Events, BARC: Bleeding Academic Research Consortium, VARC: Valve Academic Research Consortium

This article is protected by copyright. All rights reserved. 
Table 3. Adjusted odds of efficacy endpoints, TAVR Eligibility

According to LES $\geq 18$ vs. According to Heart Team Assessment Despite LES $<18$

OR $95 \%$ CI

P-value

\section{8 hours or at discharge}

NACE

MACE

Death

MI

Stroke

Major vascular complications

$\mathrm{BARC} \geq 3 \mathrm{~b}$

VARC life-threatening bleeding

30 days

NACE

MACE

Death

MI

Stroke

Major vascular complications

BARC $\geq 3 b$

BAR

VARC life-threatening bleeding
1.48

1.79

1.28

9.93

1.23

1.07

1.38

1.03

1.32

1.27

0.91

1.49

1.41

0.97

1.38

0.99
$0.89-2.45$

$0.79-4.05$

$0.38-4.36$

$0.49-201.35$

$0.38-3.96$

$0.72-1.60$

$0.78-2.44$

$0.70-1.51$

0.86 - 2.02

0.21

$0.72-2.25$

0.41

$0.43-1.92$

0.80

$0.33-6.68$

0.61

$0.57-3.47$

0.45

$0.65-1.44$

0.88

$0.82-2.33$

$0.69-1.41$
0.13

0.16

0.69

0.14

0.73

0.73

0.26

0.89

LES: Logistic EuroSCORE, OR: Odds Ratio, CI: Confidence Interval, NACE: Net Adverse Cardiovascular Events, MACE: Major Adverse Cardiovascular Events, BARC: Bleeding Academic Research Consortium. VARC: Valve Academic Research Consortium. OR's adjusted for age, sex, diabetes mellitus, CKD, COPD, LVEF, atrial fibrillation and country.

This article is protected by copyright. All rights reserved. 


\section{University Library}

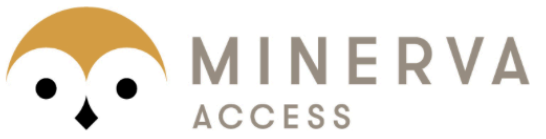

A gateway to Melbourne's research publications

Minerva Access is the Institutional Repository of The University of Melbourne

\section{Author/s:}

Camaj, A;Claessen, BE;Mehran, R;Yudi, MB;Power, D;Baber, U;Hengstenberg, C;Lefevre, T;Van Belle, E;Giustino, G;Guedeney, P;Sorrentino, S;Kupatt, C;Webb, JG;Hildick-Smith, D;Hink, HU;Deliargyris, EN;Anthopoulos, P;Sharma, SK;Kini, A;Sartori, S;Chandrasekhar, J;Dangas, GD

Title:

The importance of the Heart Team evaluation before transcatheter aortic valve replacement: Results from the BRAVO-3 trial

Date:

2020-01-13

\section{Citation:}

Camaj, A., Claessen, B. E., Mehran, R., Yudi, M. B., Power, D., Baber, U., Hengstenberg, C., Lefevre, T., Van Belle, E., Giustino, G., Guedeney, P., Sorrentino, S., Kupatt, C., Webb, J. G., Hildick-Smith, D., Hink, H. U., Deliargyris, E. N., Anthopoulos, P., Sharma, S. K. ,... Dangas, G. D. (2020). The importance of the Heart Team evaluation before transcatheter aortic valve replacement: Results from the BRAVO-3 trial. CATHETERIZATION AND CARDIOVASCULAR INTERVENTIONS, 96 (7), pp.E688-E694. https://doi.org/10.1002/ccd.28717.

Persistent Link:

http://hdl.handle.net/11343/275260 